\title{
TITANITA-BIOTITA GRANITOS DO BAIXO RIO UAUPÉS, PROVÍNCIA RIO NEGRO, AMAZONAS. PARTE I: GEOLOGIA, PETROGRAFIA E GEOCRONOLOGIA
}

\author{
ROBERTO DALL'AGNOL* \& MOACIR J. B. MACAMBIRA*
}

\begin{abstract}
TITANITE-BIOTITE GRANITES OF THE UAUPÉS RIVER, RIO NEGRO PROVINCE, AMAZONAS STATE BRAZIL. PART I: GEOLOGY, PETROGRAPHY AND GEOCHRONOLOGY. Titanitebiotite granitoids and gneisses are dominant rocks in the Rio Negro Province (RNP), NW Amazonas State, Brazil. Batholithic bodies, composed of these rocks, outcrop in the Low Uaupés River area. In this region, little deformed titanite-biotite monzogranites (TBMG) are the major rock type. The granites of this area are here named Rio Uaupés Granite (RUG). Their principal petrographic characteristics are: relatively low modal quartz; significantly high anorthite contents of plagioclase (cores of calcic andesine); extremely high average modal percentages oftitanite + opaques (magnetite + ilmenite \pm pyrite) + apatite $(4.7 \%$ in the TBMG). Magnetic susceptibility measured on hand samples is systematically high in the TBMG $\left(395.3\right.$ to $\left.189.7 \times 10^{-4} \mathrm{SI}\right)$, decreasing in the hololeucocratic fades $(108.9$ to $21.2 \times 10^{4} \mathrm{SI}$ ). Therefore, the RUG are classified as magnetite series granites. Rb-Sr whole rock isochronic dating of RUG gives an age of $1459 \pm 32$ Mawith ${ }^{87} \mathrm{Sr}{ }^{86} \mathrm{Sr}$ ) initial ratio ofO.70631 \pm 0.00117 , suggesting that the RUG magma formed directily from crustal rocks or was derived from mantle sources but suffered strong crustal contamination. ConcemingthetectonicevolutionofRNP, acontinental collision model is coherent with the available information, but more geological and structural data are necessary to demonstrate this hypothesis.
\end{abstract}

Keywords: Granitogenesis, RioNegro Province, Amazônia, Rb-Sr geochronology, magnetic susceptibility, magnetite series granites, Middle Proterozoic.

RESUMO Titanita-biotita granitóides e gnaisses são as rochas dominantes na Província Rio Negro (PRN), que se situa na porção noroeste do Estado do Amazonas e se estende pelos territórios de Venezuela e Colômbia. Corpos batolíticos, formados por esses granitóides, afloram no baixo curso do Rio Uaupés. Titanita-biotita monzogranitos (TBMG), pouco deformados, são o tipo petrográfico dominante. Tais granitos são designados neste trabalho como Granito Rio Uaupés (GRU). Suas principais características petrográficas são: conteúdos modais de quartzo relativamente baixos; plagioclásio bastante cálcico, com núcleos de andesinabem preservados; porcentagens modais de titanita+ppacos (magnetita+ilmenita \pm pirita)+apatita extremamente altas (em média, 4,7\% nos TBMG). Medidas de suscetibilidade magnética (SM) em amostras de mão acusam sistematicamente valores elevados no TBMG $\left(395,3\right.$ a 189,7 x $\left.10^{-4} \mathrm{SI}\right)$, decrescendo nas fácies hololeucocráticas $\left(108,9 \mathrm{a} 21,2 \times 10^{4} \mathrm{SI}\right)$. Esses dados mostram que o GRU é um granito da série com magnetita. Uma isócrona $\mathrm{Rb}-\mathrm{Sr}$ em rocha total do GRU forneceu idade de $1459 \pm 32 \mathrm{Ma}$ com razão inicial "Sr/^ $\mathrm{Sr}$ igual a0,70631 $\pm 0,00117$, sugerindo que o magma gerador do GRU foi formado diretamente a partir de rochas crustais ou derivou-se de fonte mantélica, mas foi afetado por forte contaminação crustal. Apesar daescassez de dados geológicos e estruturais não permitir uma conclusão sobre o modelo de evolução tectônicada PRN, estes autores consideram que um modelo de colisão continental é o mais coerente com as informações disponíveis.

Palavras-chaves: Granitogênese, Província RioNegro, Amazônia, geocronologiaRb-Sr, susceptibilidade magnética, granitos com magnetita, Proterozóico Médio.

INTRODUÇÃ̃O A evolução do Cráton Amazônico estende-se do Arqueano ao Proterozóico Superior. Em trabalhos anteriores, foram discutidas as mais importantes gerações de granitóides da Amazônia (Dall'Agnol et al. 1987, Issler \& Lima 1987), ficando evidentes as estreitas relações entre o magmatismo granítico e a história geológica das diversas províncias tectônicas do Cráton Amazônico. A Província Rio Negro (PRN) adquire importância particular por ser marco essencial da evolução do cráton durante o Proterozóico Médio. Além disso, a sua granitogênese, embora pouco estudada, parece diferir substancialmente daquela presente em outras províncias da região.

Muitos autores têm procurado estabelecer paralelos entre gerações de granitóides e ambientes tectônicos, partindo das características geoquímicas dos primeiros (Pearce et al. 1984, Harris et al. 1986, Maniar \& Piccoli 1989, Rogers \& Greenberg 1990). Outros autores têm acentuado as peculiaridades da granitogênese e evolução tectônica do Proterozóico Médio (Anderson \& Bender 1989). A importância da natureza dos opacos e da suscetibilidade magnética em rochas granitóides também tem sido enfatizada (Ishihara 1981,
Dall'Agnol et al. 1988, Magalhães 1991, Magalhães \& Dall'Agnol inéd.).

Pelo exposto, foi desenvolvido um estudo petrológico, geoquímico e geocronológico dos titanita-biotita granitóides do baixo Rio Uaupés na PRN, por serem representativos de um dos tipos de magmatismo granítico mais expressivo da província. O objetivo é obter melhor compreensão de sua gênese e da evolução dessa província, contribuindo, ao mesmo tempo, para estabelecer paralelos com granitóides formados no mesmo período em outras regiões do Cráton Amazônico e do Globo. Este trabalho é dividido em duas partes: na primeira, serão discutidos essencialmente os aspectos relativos à petrografia, suscetibilidade magnética e geocronologia.

CONTEXTO GEOLÓGICO A região estudada situase na porção centro-sul da folha Pico da Neblina, na Bacia do alto Rio Negro, no extremo NW do Estado do Amazonas e do Brasil, próxima das fronteiras com Venezuela e Colômbia (Fig. 1). Ela está compreendida na Província Rio NegroJuruena, conforme definida por Tassinari (1981), Cordani \& 


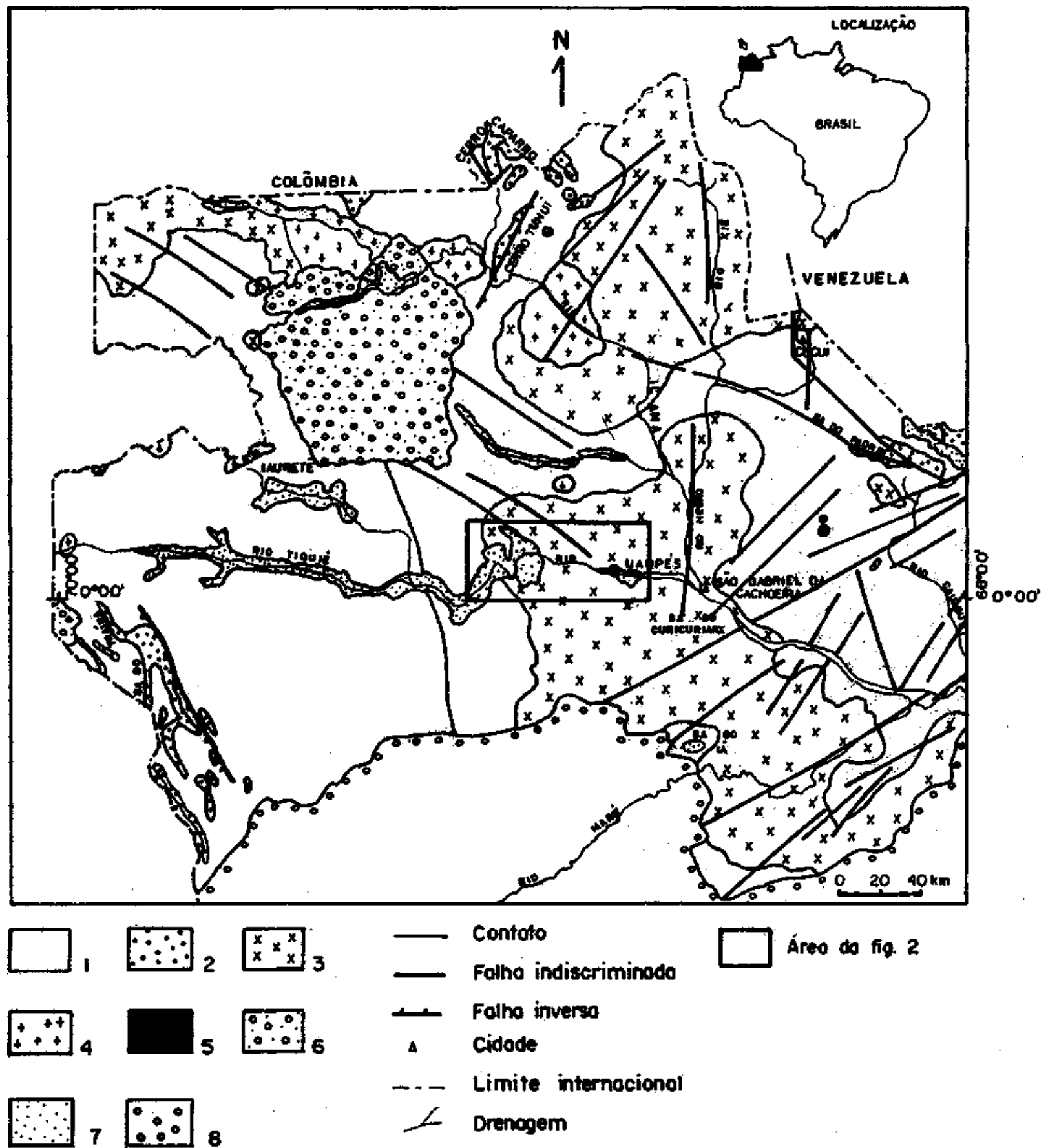

Figura 1 - Esboço deporte da Província Rio Negro, no extremo N W do Estado do Amazonas. (Baseado em Lima \& Pires 1985, Fig.1, simplificado). 1. Complexos gnáissicos indiferenciados; 2. Grupo Roraima (inclui o Grupo Tunui); 3. Suite Intrusiva Rio Vaupés; 4. Suite Intrusiva Rio Içana; 5. Carbonatito Seis Lagos; 6. Cobertura detritico-laterítica; 7. Aluviões e coluviões; 8. Formação Solimões

Figure 1 -Geological map of part of the Rio Negro Province, N W of Amazonas State, Brazil. (Modified from Lima \& Pires 1985). 1. Undifferentiated gneissic complexes; 2. Roraima Group (includes the Tunuí Group); 3. Rio Uaupés Intrusive Suite; 4. Rio Içana Intrusive Suite; 5. Seis Lagos Carbonatite; 6. Younger detritic and lateritic covers; 7. Alluvial and colluvial deposits; 8. Solimões Formation

Brito Neves (1982) e Teixeira et al. (1989); foi pesquisada pioneiramente por Paiva (1929) e, na década de 70, pelo Projeto RADAMBRASIL (Pinheiro et al. 1976, Dall'Agnol \& Abreu 1976, Fernandes et al. 1977). Dall'Agnol (inéd.) efetuou uma revisão da geologia da PRN e discutiu a possível evolução petrológica de suas principais rochas, ao passo que Lima \& Pires (1985) propuseram um modelo tectônico e uma série de novas unidades para a geologia local, com base na reinterpretação de imagens de radar e dos dados acumulados na década anterior. Tassinari (1984) divulgou dados geocronológicos adicionais sobre granitóides e gnaisses da Folha Pico da Neblina.

Dall'Agnol et al (1987) discutiram a granitogênese da PRN, resumindo os aspectos mais importantes de sua geologia. Segundo esses autores, a PRN mostra diferenças notáveis em relação a outros domínios do Cráton Amazônico: 1. os 


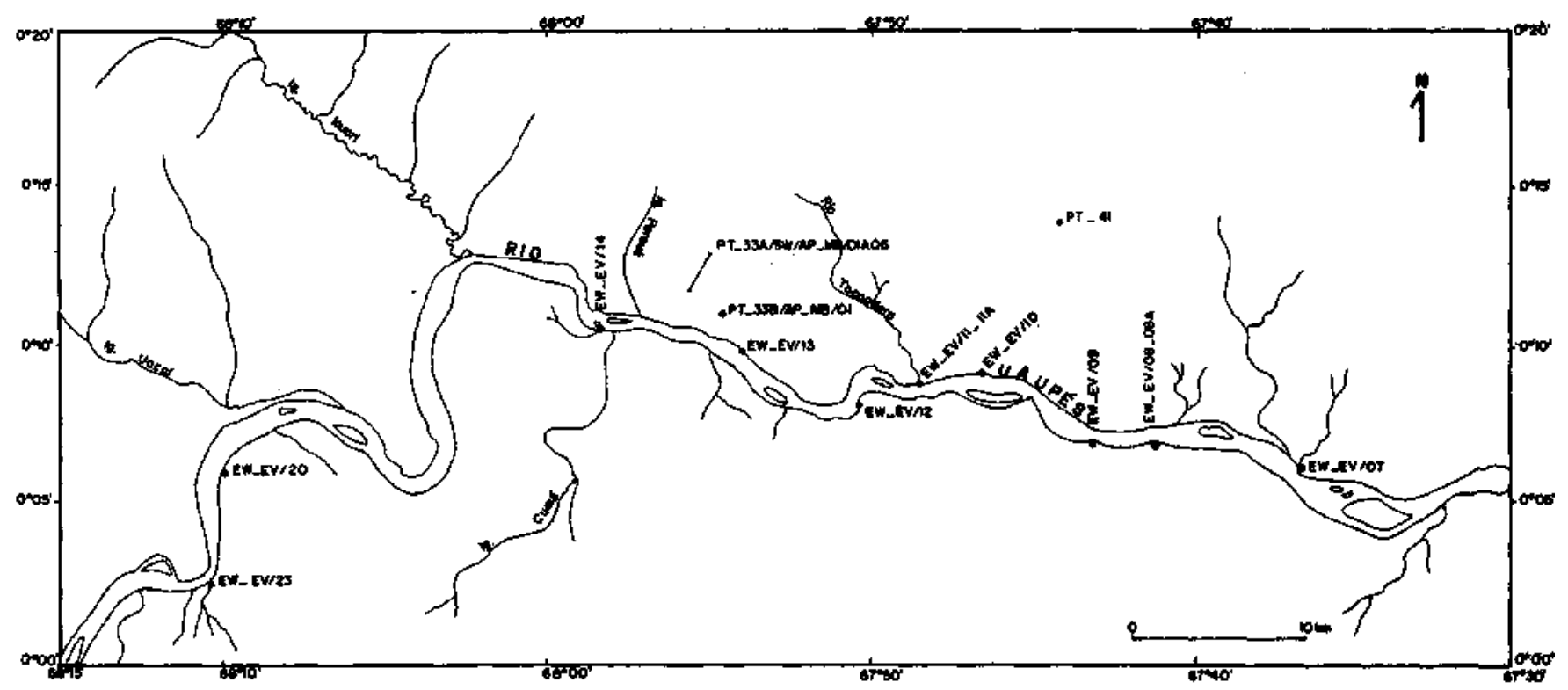

Figura 2 - Mapa de amostragem

Figure 2 - Sampling map

dados geocronológicos disponíveis são em número expressivo e sugerem que a maioria, senão a totalidade das rochas da província, formou-se após o evento Transamazônico; 2 . a geologia da PRN contrasta vivamente com aquela descrita em típicos terrenos gramto-greenstone, como é o caso de Amapá e Sul do Pará; 3. não foram descritas seqüências granulíticas expressivas na PRN; 4. não há, na PRN, ocorrências mapeadas de granitos similares aos granitos anorogênicos, que são amplamente distribuídos no cráton, e as rochas vulcânicas ácidas conhecidas limitam-se às ocorrências do Rio Traíra, que são mais jovens que o Vulcanismo Uatumã (Fernandes et al. 1977). Cordani \& Brito Neves (1982) e Teixeira et al. (1989) consideram que a PRN estende-se para a porção sul do cráton, definindo a Província Rio Negro-Juruena como formada entre 1750-1500 Ma. Tassinari (1981) relacionou a evolução desta província a um arco magmático do Proterozóico Médio, envolvendo subducção de crosta oceânica e importante contribuição mantélica. Dall'Agnol et al. (1987) adotaram a hipótese alternativa de colisão continental entre a Província Amazônia Central e as províncias Juruena (porção ocidental) e Rondônia. Este evento seria o responsável pela evolução peculiar apresentada pela PRN, incluindo a granitogênese.

A geologia da PRN é dominada por uma complexa associação de rochas granitóides e gnáissicas, cuja interpretação e eventual separação tem sido dificultada pela pequena escala dos mapas geológicos disponíveis. Dali'Agnol \& Abreu (1976) distinguiram nessa região três principais grupos de rochas: 1. biotita granitóides e gnaisses com titanita e anfibólio; 2. granitóides e gnaisses com duas micas; 3. anfíbolitos e rochas meta-básicas. Os granitóides e gnaisses do primeiro grupo são as rochas de mais ampla distribuição nas folhas Pico da Neblina e Içá e existe uma perfeita coincidência entre as paragêneses encontradas em ambos. Um esboço da geologia de parte da PRN é apresentado na figura 1 que baseia-se em Lima \& Pires (1985, Fig. 1).

Com base no exame da amostragem feita pelo Projeto RADAMBRASIL na folha Pico da Neblina, selecionou-se a região do baixo Rio Uaupés e adjacências para o presente estudo por ser o local onde se tem a ocorrência mais expressiva dos biotita granitóides com titanita. Nessa área, os mesmos apresentam-se pouco deformados, com texturas muito uniformes e sem estruturas gnáissicas, aflorando numa extensão de, pelo menos, $40 \mathrm{~km}$ e formando, ao que tudo indica, um corpo granítico de dimensões batolíticas. $\mathrm{Na}$ figura 2 é fornecido um mapa com a localização das amostras estudadas, todas coletadas pelo Projeto RADAMBRASIL.

REVISÃO DA NOMENCLATURA ESTRATIGRÁFICA

Paiva (1929) efetuou o levantamento geológico dos rios Negro, Uaupés, Içana, Aiari, Cassiquiari e parte do Orenoco e destacou a dominância nessa região de granitos e granitos gnaissificados que correlacionou ao "Complexo Fundamental do Núcleo Brasileiro". Dall'Agnol et al. (1987) assinalou, ainda, que "nas proximidades da boca do Vaupés o caracter macisso do granito regional é um traço distinctivo em relação aos typos orientados do alto rio e do Ayari" (Paiva 1929, p.59). Esse autor estabeleceu clara distinção entre os granitóides e gnaisses com duas micas do Rio Içana e o que ele denominou de "magmaprimordial da bacia do rio Negro ", que corresponde ao seu granito regional e ao titanitabiotita granito destes autores.

Lima \& Pires (1 985) delimitam aproximadamente as áreas de dominação dos dois tipos de granitos citados, e as áreas onde ocorrem complexos gnáissicos. Eles propuseram a designação Suíte Intrusiva Curicuriari para o conjunto de titanita-biotita granitóides, incluindo os granitos do baixo Rio Uaupés. Sugeriram, adicionalmente, a designação Complexo Rio Uaupés para rochas gnáissicas muito pouco estudadas presentes em áreas restritas do trecho superior do rio homônimo.

Considerando: 1. o valor histórico do trabalho de Paiva (1929); 2. as limitadíssimas informações disponíveis sobre as rochas da Serra do Curicuriari; 3. a definição inadequada do Complexo Rio Uaupés, apoiada em dados insuficientes; 4. o acervo muito mais significativo de dados petrográficos, químicos e geocronológicos disponíveis sobre os titanita-biotita granitóides a partir deste estudo, propõe-se:

a. a designação de Granito Rio Uaupés para os titanita-biotita granitóides e rochas associadas ocorrentes no trecho inferior do rio homônimo;

b. o trecho do Rio Uaupés, compreendido entre as longitudes de $67^{\circ} 30^{\prime}$ e $68^{\circ} \mathrm{W}$, como sua seção-tipo;

c. a denominação de Suíte Intrusiva Rio Uaupés para os 
Tabela 1 - Composições modais e valores de suscetibilidade magnética do Granito Rio Uaupés Table 1 - Modal compositions and magnetic susceptibility values of the Rio Uaupés Granite

\begin{tabular}{|c|c|c|c|c|c|c|c|c|c|c|c|c|}
\hline \multirow{2}{*}{$\begin{array}{c}\text { CLASSIFICACAO } \\
\text { MINERAIS }\end{array}$} & \multirow{2}{*}{$\begin{array}{c}\text { GRANODIORITO } \\
\text { UA.20 }\end{array}$} & \multicolumn{8}{|c|}{ Tit - BI MONZOGRANITO (TBMG) } & \multicolumn{2}{|c|}{$\begin{array}{c}\text { LEUCOMONZOGR } \\
\text { (LMG) }\end{array}$} & \multirow{2}{*}{$\begin{array}{c}\begin{array}{c}\text { LEUCO-SIENOG } \\
\text { (LSG) }\end{array} \\
\text { UA-23 }\end{array}$} \\
\hline & & UA-7 & 3381 & UA-8 & UA-11 & $33 \mathrm{AB}$ & 334.5 & 33A1 & MEDAA & UA-13 & UA-14 & \\
\hline Quanzo & 33,9 & 22,8 & 23,8 & 27,1 & 20,2 & 27,1 & 20,9 & 26.0 & 24,0 & 22,9 & 44,9 & 43,2 \\
\hline Plagioclásio (P) & 42,2 & 31,4 & 29,0 & 33.3 & 29,5 & 32,0 & 35,0 & 28,7 & 31,2 & 26,7 & 23,3 & 14,2 \\
\hline Foldsp. Potass. (Fp) & 9,8 & 33.2 & $\mathbf{3 2 , 0}$ & 28.4 & 35.3 & 26,9 & 21,1 & 33,1 & 29,9 & 48,2 & 30,0 & 41,9 \\
\hline Biotila & 11,5 & 9,4 & 8,0 & $7, \mathrm{~B}$ & 6,6 & 7,7 & 13.4 & 7,6 & 8,6 & 1,3 & 2,2 & 0,6 \\
\hline Anfibolio & - & - & 2.3 & * & 2.1 & 1.4 & 0.6 & 1.1 & 1.1 & - & - & - \\
\hline Titanita (Tit) & 0.8 & 1,0 & 2,8 & 2,3 & 3,5 & 2,7 & 3,8 & 1,3 & 2,5 & 1,8 & - & 0,1 \\
\hline Opacos $(O p)$ & 0,5 & 1,3 & 1.5 & 0,9 & 0.9 & 1,3 & 3,9 & 1,3 & 1,6 & 0.5 & 0.3 & 0.1 \\
\hline Apatta (Ap) & 0,1 & 0,6 & 0,4 & 0,2 & 0,6 & 0,5 & 1.1 & 0,6 & 0,6 & - & - & - \\
\hline Epidoto & 1.5 & 0.3 & . & - & 1,0 & 0.3 & - & 0,1 & 0,2 & 0,1 & 0.1 & - \\
\hline Clonita & 0,1 & - & 0,1 & - & 0,1 & - & 0,2 & 0,1 & 0.1 & - & - & $\cdot$ \\
\hline Acessónios & * & $=$ & 0.1 & - & $=$ & 0,1 & 0,1 & 0,1 & 0.1 & 0,5 & - & - \\
\hline$N^{*}$ de Pontos & 2140 & 2023 & 2072 & 2064 & 2140 & 2057 & 2070 & 5500 & 2561 & 2174 & $2 \div 27$ & 2107 \\
\hline Comp. $\mathrm{Pl}^{*}$ (An) & $46-21$ & n.d. & $32-7$ & n.d. & 40.13 & $50-13$ & n.d. & 37.11 & - & $36-13$ & n.d. & 37.16 \\
\hline Indice de cor (M) & 14,3 & 12,8 & 15,2 & 11,2 & 15,0 & 14,0 & 23,0 & 12,2 & 14,6 & 4,2 & 2,6 & 0,7 \\
\hline $\mathrm{PI}+\mathrm{Fp}$ & 51,8 & 64,6 & 61,0 & 61,7 & 64,8 & 58.9 & $5 \theta, 1$ & 61,8 & 61,2 & 72,9 & 53,3 & 56,1 \\
\hline$T i t+O p+A p$ & 1,2 & 2.9 & 4,7 & 3.4 & 5,2 & 4.5 & 8.7 & 3.2 & 4.7 & 2,3 & 0,3 & 0.1 \\
\hline Suscet Magn." & $189 ; 7$ & 218,9 & 271,6 & 327,4 & 245,0 & 305,3 & 276,5 & 366,2 & 306,3 & 74,2 & 108,9 & 21,2 \\
\hline
\end{tabular}

* Exciuldas as bordas albiticas; $n, d_{2}=$ năo determinada; outras lâminas: $A n_{46-21}, A n_{15-23}$.

$$
\text { ** SI }\left(\times 10^{-4}\right)
$$

diversos corpos granitóides petrologicamente afins ao Granito Rio Uaupés e relacionados ao mesmo evento magmático.

PETROGRAFIA As amostras disponíveis na área foram todas laminadas e descritas microscopicamente. Foram feitos análise textural e estudo detalhado do zoneamento dos plagioclásios na variedade de rocha dominante. Com base na petrografia, foram selecionadas onze amostras representativas do conjunto estudado para análises químicas. As mesmas tiveram suas composições modais determinadas com um contador de pontos, marca Swift. Foi utilizada apenas uma seção delgada para cada amostra - abaixo, portanto, do mínimo exigido para rigorosa precisão estatística -, e foram computados em torno de 2.000 pontos por seção, o que se enquadra nos padrões recomendados (Chaves 1956).

Composições modais Os resultados das análises modais (Tab. 1) e os diagramas Q-A-P e Q-(A+P)-M (Fig. 3) permitem classificar as rochas estudadas como biotitagranodiorito (BGD), titanita-biotita monzogranito (TBMG), leucomonzogranito (LMG) e leuco-sienogranito (LSG), com base na nomenclatura sugerida pela IUGS (Streckeisen 1976). A única amostra classificada como granodiorito tem teores de quartzo e epídoto bem superiores aos determinados nos monzogranitos, ao passo que ocorre o inverso com o somatório de titanita + opacos +apatita. Ela foi coletada em ponto relativamente distante da área de concentração dos monzogranitos (Fig. 2); porém, alinhou-se na isócrona $\mathrm{Rb}-\mathrm{Sr}$ com os mesmos (Fig. 7).
O BGD e TBMG têm a biotita como principal constituinte ferromagnesiano. $\mathrm{O}$ anfibólio ocorre em boa parte dos TBMG, porém, suas porcentagens são sempre baixas, inferiores às da titanita e, em média, à dos opacos. Nos TBMG, a associação titanita (Tit) + opacos (Op) + apatita (Ap) perfaz, em média $4,7 \%$ dos constituintes modais - titanita atinge cerca de $2,5 \%$ e se caracteriza, portanto, como constituinte varietal. A proporção média de opacos $(1,6 \%)$ também é grande para granitos. Os valores de $\mathrm{M}$ dos TBMG situam-se entre $11 \mathrm{e}$ $16 \%$, atingindo excepcionalmente valores acima de $20 \%$. O valor obtido no BGD é similar à média dos TBMG. Nestes as porcentagens de quartzo não são muito elevadas, embora sempre superiores a $20 \%$.

Os leucogranitos $(M<5)$ estudados apresentam diferenças significativas entre si. Os dois LMG diferem muito em teores de quartzo e de minerais máfícos. EV-13 tem muitas afinidades petrográficas com os TBMG, possuindo igualmente proporções expressivas de Tit+Op+Ap. Tanto o LMG E V-14, quanto o LSG EV-23, correspondem a rochas muito enriquecidas em quartzo; suas afinidades com o TBMG são menos evidentes.

DalPAgnol et al. (1987) sugeriram que os titanita-biotita granitóides da PRN pertenceriam a série subalcalina monzonítica (Bowden et al. 1984). A franca dominação de monzogranitos no Granito Rio Uaupés e a ausência de termos quartzo-monzoníticos e monzoníticos entre as amostras estudadas não fortalecem a referida hipótese. É necessário um número mais expressivo de dados para que se possa concluir a respeito. 


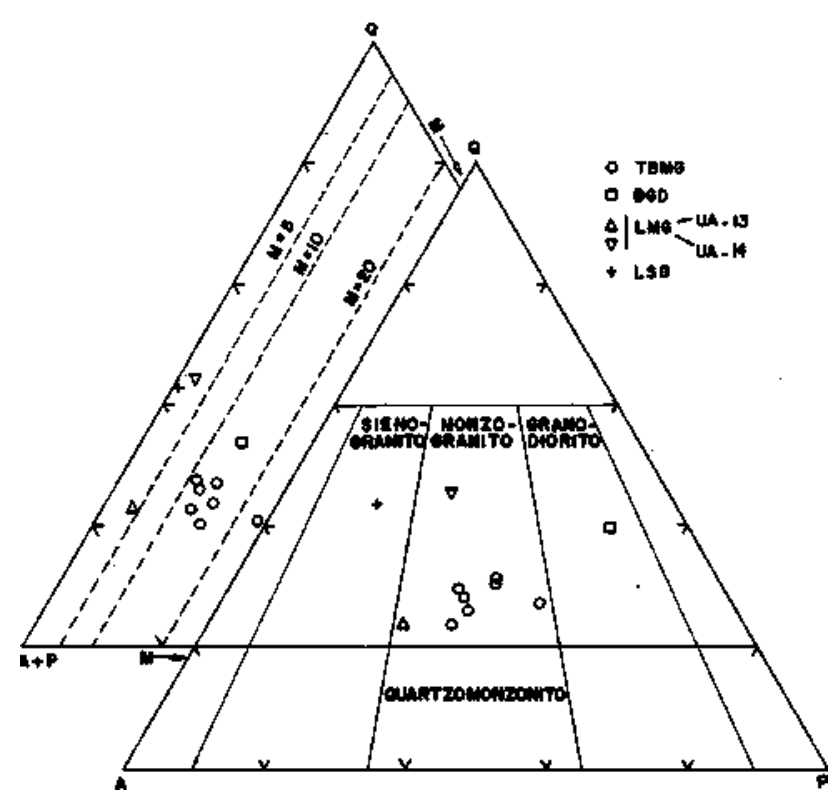

Figura 3 - Diagramas $Q-A-P$ e Q-(A+P)-Mdo Granito Rio Uaupés. (Campos e classificação conformeStreckeisen 1976). Símbolos: titanita-biotita monzogranitos (TBMG) - círculos vazios; biotita granodiorito (BGD) - quadrado vazio; leucomonzogranitos(LMG): UA-13-triàngulovazio; UA-23triângulo vazio invertido; leuco-sienogranito (LSG) - cruz Figure 3 - Q-A-P and Q-(A+P)-M plots of the Rio Uaupés Granite (Fields and classification following Streckeisen 1976). Symbols: titanite-biotite monzogranites (TBMG) - open circles; biotite granodiorite (BGD) - open square; leucomonzogranites (LMG)- UA-13 -open triangle; UA-23-inversed open triangle; leucosyenogranite (LSG)-cross

Aspectos macroscópicos Os TBMG e BGD apresentam aspecto macroscópico muito semelhante, sendo ambos faneríticos, equigranulares com granulação média a grossa e de cor cinza quando frescos, passando a castanha quando algo alterados. O plagioclásio e o feldspato potássico apresentam tonalidades muito próximas; não é fácil a sua separação macroscópica. Os minerais máficos apresentam-se em agregados de cor escura, conferindo aspecto mosqueado à rocha. Os LMG e LSG também apresentam granulação média ou média a fina - seus grãos têm dimensões menores que os dominantes nos TBMG e BHGD, a cor é cinza claro e são acentuadamente leucocráticos. Não há nenhuma foliação perceptível nas amostras estudadas - todas francamente isotrópicas.

Aspectos microscópicos TITANITA-BIOTITA MONZOGRANITOS (TBMG) Ao microscópio, os TBMG exibem textura granular hipidiomórfíca, notando-se o maior desenvolvimento dos feldspatos (3 a $10 \mathrm{~mm}$ ) em relação a quartzo e minerais máficos (1 a $4 \mathrm{~mm}$ ). As texturas observadas são tipicamente ígneas, não havendo evidências significativas de recristalização dos minerais ou de deformação intensa. $\mathrm{O}$ quartzo $(\mathrm{Qz})$ ocorre em porcentagens pouco inferiores àquelas dos feldspatos. E possível distinguir quatro tipos texturais: 1. Qz, xenomorfo e com dimensões geralmente entre 1 e $4 \mathrm{~mm}$, é o tipo dominante. Costuma dispor-se em agregados entre os grãos maiores de feldspatos e assume muitas vezes disposição intersticial. Acha-se, por vezes, deformado e com forte extinção ondulante. 2. $\mathrm{Qz}_{2}$ tem granulação muito fina $(<0,5 \mathrm{~mm})$, apresentando-se em glóbulos ou, localmente, corroído, sempre xenomorfo e incluso no feldspato potássico ou, muito raramente, no plagioclásio. Comumente, as inclusões de $\mathrm{Qz}_{2}$ dispõem-se aleatoria- mente no cristal hospedeiro, mas podem alinhar-se paralelas à borda do mesmo. 3. Qz 3 corresponde àquele presente nos intercrescimentos mirmequíticos, que são muito freqüentes nos contactos plagioclásio-feldspato alcalino e também feldspato alcalino-feldspato alcalino, muitas vezes associados a coroas-albíticas trocadas (swapped-rims, de Ramberg 1962 e Smith 1974). 4. Qz $\mathrm{z}_{4}$ é muito localizado, xenomorfo e de granulação fina $(<0,4 \mathrm{~mm})$, associando-se sempre aos máficos. Forma simplectitos com o anfibólio ou contém granules desse mineral.

As porcentagens médias de feldspato potássico $(\mathrm{Fp})$ e plagioclásio (P1) praticamente se eqüivalem. O Fp mostra sempre geminação albita-periclínio muito nítida, sugerindo que possua triclinicidade alta e corresponda, portanto, a um microclínio. Seu aspecto é sempre límpido. Costuma ser pobre em pertitas, que são finas e irregularmente distribuídas nos cristais. Os cristais geralmente são subautomorfos, mas há lâminas contendo cristais automorfos e outras em que grãos xenomorfos predominam. As inclusões de $\mathrm{Qz}_{2}$ são relativamente freqüentes, ao passo que aquelas de $\mathrm{P} 1$ e biotita são raras. As inclusões de Pl acham-se fortemente corroídas e envoltas por plagioclásio sódico (albita?). Nos contatos Fp$\mathrm{Pl}$ há sempre auréolas comparativamente mais sódicas que o restante do P1, geralmente associadas com mirmequitas. Nos contatos Fp-Fp, é comum albita intergranular que pode apresentar-se como coroas trocadas e ter texturas mirmequíticas.

O plagioclásio desenvolve cristais subautomorfos de hábito tabular, que fornecem geralmente seções bastante alongadas segundo os eixos c e a nas seções (100) e (001), respectivamente, e algo alongadas segundo o eixo a nas seções (010). Os geminados polissintéticos segundo a lei da albita, são muito mais freqüentes que os geminados periclínio. Os geminados duplos albita-carlsbad são também muito comuns. Os geminados estão bem marcados, permitindo estudo mais acurado do zoneamento e composição do plagioclásio, nas seções (100) e (010), por meio dos métodos do ângulo de extinção e da sua posição em relação às clivagens e da dupla geminados albita-carlsbad. Foi observado, sempre, zoneamento normal, sem oscilações perceptíveis, indo desde andesina até oligoclásio ou mesmo albita, geralmente com três a até cinco zonas de composições distintas em um mesmo cristal. A maioria dos cristais estudados possui núcleos de andesina sódica $\left(\mathrm{An}_{37 \pm 2}\right)$, que gradam para oligoclásio cálcico $\left(\mathrm{An}_{23 \pm 2}\right)$ através de uma ou mais zonas intermediárias. Este intervalo corresponde à maior porção dos cristais, envolve o núcleo e a zona intermediária. Elas são seguidas muitas vezes por franjas estreitas e descontínuas de oligoclásio sódico $\left(\mathrm{An}_{13 \pm 1}\right)$ ou albita (An.7-0), desenvolvidas quase sempre junto aos contactos com o Fp. Em duas amostras, foi constatada a presença de núcleos mais cálcicos $\left(\mathrm{An}_{50-45}\right)$, seguidos por zonas similares às observadas nos demais cristais. Tanto esses núcleos quanto os de andesina sódica acham-se aparentemente corroídos, sugerindo desequilíbrio com o avanço da cristalização. São geradas manchas mais sódicas nas zonas centrais (patchy zoning). As bordas sódicas podem associar-se a intercres- cimentos mirmequíticos. São comuns os agregados de cristais, sugerindo relações de synneusis (no sentido de Vance 1969), as quais não são inequívocas, podendo ser interpretadas de outro modo (Dowry 1980, Smith \& Brown 1988). O caráter bastante cálcico do plagioclásio certamente é responsável pelos teores expressivos de $\mathrm{CaO}$ obtidos nestes granitos. O P1 altera-se pouco intensamente para sericita, epídoto e, raro, carbonates. Ele engloba cristais de anfibólio, biotita corroída, minerais acessórios e $\mathrm{Qz}_{2}$ (apenas nas bordas sódicas). Muitas vezes, é possível perceber que são zonas mais sódicas do P1 que envolvem as inclusões destes minerais. São comuns manchas de Fp no P1 e microinclusões de minerais com alto relevo e birrefringência (rutilo?). Localmente, o P1 acha-se deformado, conforme revelam kink-bands afetando seus geminados. 
A biotita (Bt) exibe pleocroísmo de amarelo castanho a marrom ou, mais raramente, verde oliva. Não se acha muito alterada, sendo muito limitada a formação de clorita ou a oxidação de suas lamelas. Essas, formam geralmente agregados, juntamente com os demais minerais máficos. É marcante e constante a corrosão interna de seus cristais, que parecem amoldar-se aos grãos de quartzo e feldspatos, sugerindo a cristalização tardia da mica. Essa interpretação também é reforçada pelo fato da $\mathrm{Bt}$ assumir muitas vezes aspecto poiquilítico, englobando grande quantidade de acessórios, hornblenda e quartzo. Entretanto, essa hipótese é contraditória com a ocorrência de cristais corroídos de $\mathrm{Bt}$ no interior de grãos de plagioclásio andesínico e, eventualmente, de Fp. É possível que a disposição "intersticial" da mica seja apenas aparente e que sua cristalização não seja tardia. Embora se observe com relativa freqüência reabsorção parcial de $\mathrm{Bt}$ em granites (cf. Borrei 1978), ela não costuma ser tão intensa como nos TBMG e a sua causa precisaria ser melhor compreendida. Uma possível explicação seria a de que tais agregados representem resíduos de fusão do material gerador do magma granítico, mas não há elementos para concluir a respeito. Uma feição notável da Bt é a sua riqueza em inclusões de apatita, zircão, opacos e titanita, acompanhadas, por vezes, de rutilo (?) e epídoto. Os dois primeiros são sempre envoltos por halos pleocróicos, que podem ou não existir em torno da titanita. A Bt mostra encurvamento de suas lamelas e extinção ondulante. Finos granules (óxidos de ferro?) são comuns ao longo de sua clivagem conferindo-lhes tonalidade mais escura.

A titanita (Tit) ocorre em três variedades texturais: a. ern cristais bem desenvolvidos com 1 a $4 \mathrm{~mm}\left(\mathrm{Tit}_{1}\right)$; b. em coroas em torno dos minerais opacos $\left(\mathrm{Tit}_{2}\right)$; c. em finos grãos, inclusos quase sempre na biotita $\left(\mathrm{Tit}_{3}\right)$. Os primeiros formam a maior parte da Tit presente nos TBMG. São xenomorfos ou, localmente, subautomorfos, preenchendo espaços entre os grãos de quartzo e feldspatos e amoldando-se aos mesmos. Geralmente, apresenta pleocroísmo em tons de marrom avermelhado e pode ou não gerar halos pleocróicos na biotita. Em certas lâminas, há nítida variação na cor da titanita em um mesmo cristal, com zonas marrom avermelhadas, pleocróicas, e outras sem pleocroísmo. As primeiras causam a formação de halos nos contatos com a biotita - o mesmo não se verifica com as últimas. É possível, portanto, que as zonas mais coloridas sejam enriquecidas em elementos radioativos. Há indicação adicional da presença desses elementos, em razão da ocorrência de cristais de Tit parcial ou totalmente metamictizados (?). A Tit ${ }_{2}$ é igualmente freqüente, desenvolvendo-se sempre nos agregados de máficos onde se concentram os opacos. As coroas de $\mathrm{Tit}_{2}$ costumam ser finas e esta normalmente não exibe pleocroísmo. A $\mathrm{Tit}_{3}$ também é freqüente, podendo ser xenomorfa ou subautomorfa. Por vezes, ela concentra-se nitidamente nas bordas de lamelas de biotita afetadas por corrosão (Ti liberado durante a corrosão da mica?).

$\mathrm{O}$ anfibólio associa-se a $\mathrm{Bt}$ e demais minerais máficos. Seus cristais são subédricos a anédricos, sendo com freqüência descontínuos e englobados pela mica ou $\mathrm{Qz}_{4}$. Exibem pleocroísmo de verde a verde azulado nas seções prismáticas, e de amarelo esverdeado ou verde pálido a verde nas seções basais. $\mathrm{O}$ seu sinal óptico é negativo e o ângulo $2 \mathrm{~V}$ pequeno $\left(20\right.$ a $\left.30^{\circ}\right)$. Essas características sugerem tratar-se de hornblenda hastingsítica ou de variedade similar rica em ferro (ferroedenita ou hornblenda ferro-edenítica).

Os opacos são xenomorfos ou, mais raramente, subautomorfos. As observações de seções polidas ao microscópio ótico de luz refletida e ao microscópio eletrônico de varredura demonstram que os grãos de opacos são dominantemente de magnetita, acompanhada por ilmenita (Fig. 4a,d,e) e, eventualmente, pirita (geralmente muito alterada para goethita). Os dois primeiros acham-se envoltos por coroas de titanita e foram corroídos, o que mascara sua forma primitiva (Fig. $4 \mathrm{~b}, \mathrm{~d}, \mathrm{e})$. A magnetita, de modo geral, é do tipo homogêneo não exibindo intercrescimentos com ilmenita trellis (Fig. 4a,d,e).
Isso, juntamente com a sua pobreza em titânio, mostrada pelos espectros de raios $\mathrm{X}$, indica que foi intensamente reequilibrada, e que sofreu martitização apenas incipiente. A ilmenita, quando associada à magnetita, apresenta-se sob a forma em sanduíche ou composite (Fig. 4a,b,d,e), sendo muito raros ou ausentes os grãos de ilmenita individual (cf. Magalhães 1991). A ilmenita composite possui exsoluções de hematita sob forma de lamelas com até 10 micra (Fig. 4b) ou como pontuações finíssimas de visualização difícil mesmo ao microscópio eletrônico (Fig. 4c). Os espectros de raios X revelam que as diversas variedades texturais de ilmenita possuem teores expressivos de manganês. A magnetita engloba, ocasionalmente, apatita e zircão. A primeira é automorfa e deve ser rica em minerais radioativos, pois causa a formação de halos pleocróicos na biotita, com a qual se associa preferencialmente. $\mathrm{O}$ zircão tem forma variada, podendo ser arredondado e subautomorfo ou formar cristais perfeitos. Por vezes, é possível suspeitar da existência de sobrecrescimento em torno de um núcleo primitivo.

Allanita - muitas vezes metamictizada, associada aos máficos ou inclusa na titanita - e epídoto são minerais acessórios menos abundantes. A allanita é primária e o epídoto é quase sempre secundário. A fluorita foi vista muito localmente. A clorita também não costuma ser importante, substituindo discretamente algumas lamelas de biotita.

Ordem de cristalização Apatita e zircão, seguidos de perto pelos opacos (magnetita, ilmenita composite e, provavelmente, pirita) certamente cristalizaram precocemente, devendo marcar o início de consolidação do magma (Fig. 5). O plagioclásio de composição andesínica ( $\left.\mathrm{P} 1 \mathrm{And}, \mathrm{An}_{50-35}\right)$ foi o primeiro mineral essencial a formar-se. O feldspato potássico (Fp) deve seguir-se ao PI And, e o Qz, seria, muito provavelmente, o último constituinte essencial a iniciar a sua separação do magma. Durante a cristalização do Fp e Qz, a composição do PI em equilíbrio com o magma pôde ser estimada em An . A cristalização da biotita $(\mathrm{Bt})$ é posterior à do Anf e, conforme assinalado, seu relacionamento com os minerais félsicos é ambíguo, devido à corrosão de suas lamelas e aos restos de seus cristais no interior do PI. A Tit formou-se tardiamente. $\mathrm{O} \mathrm{Qz}_{4}$ deve estar associado à transformação parcial de Anf em Bt e o $\mathrm{Qz}_{2}$ deve ser tardio. No final da cristalização, possivelmente após a saturação, ou abaixo da temperatura do solidus, deu-se a formação das bordas de PI ( $\mathrm{An}_{2}$ ou $\mathrm{An}_{?} \mathrm{p}$, e das mirmequitas, a descalcificação parcial do Pi mais cálcico, com sua substituição por epídoto e sericita, e a cloritização local da Bt. A corrosão dos núcleos andesínicos do plagioclásio revela seu forte desequilíbrio a um dado momento da cristalização magmática. As possíveis causas dessa desestabilização seriam mudanças bruscas de pressão (Vance 1965) ou efeitos sobre o magma granitóide de outro magma mais denso e mais quente (underponding, Smith \& Brown 1988). A mistura de magmas também poderia causar reabsorções em cristais de plagioclásio (Tsuchiyama 1985, Stamatelopoulou-Seymour et al. 1990). Porém, as texturas e demais dados disponíveis não favorecem essa hipótese.

Uma alternativa para o modelo proposto seria admitir que as fases texturalmente precoces (Op+Ap+Zr-f Anf) e, talvez, o plagioclásio andesínico e a biotita (esta devido à corrosão) pudessem representar minerais residuais de anatexia, carreados com o líquido em equilíbrio com os mesmos. Dessa forma, o magma gerador dos TBMG seria uma mistura de líquido com cristais em suspensão, sendo a proporção líquido/cristais elevada. Essa proporção também é válida no primeiro modelo, com a diferença que nesse as fases precoces seriam minerais cristalizados a altas temperaturas e pressões - os demais seriam formados provavelmente durante a ascensão e colocação do magma. Apesar das dúvidas assinaladas, estes autores preferem o primeiro modelo ao segundo.

BIOTITA GRANODIORITO (BGD) Ao microscópio, o 

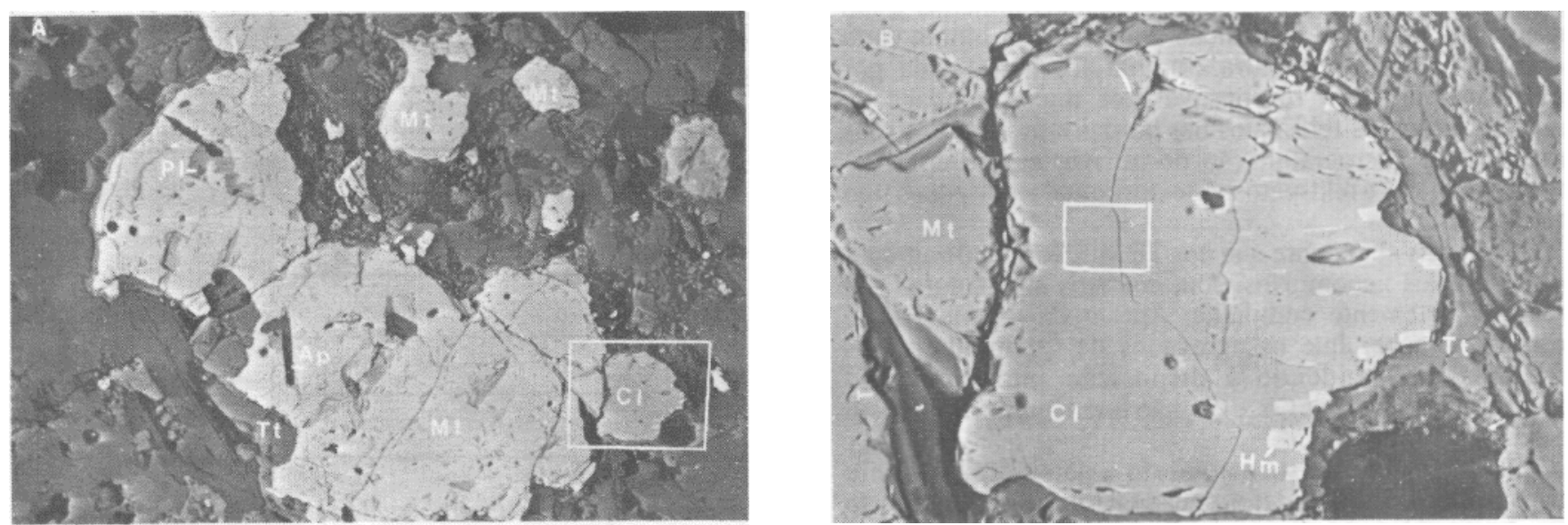
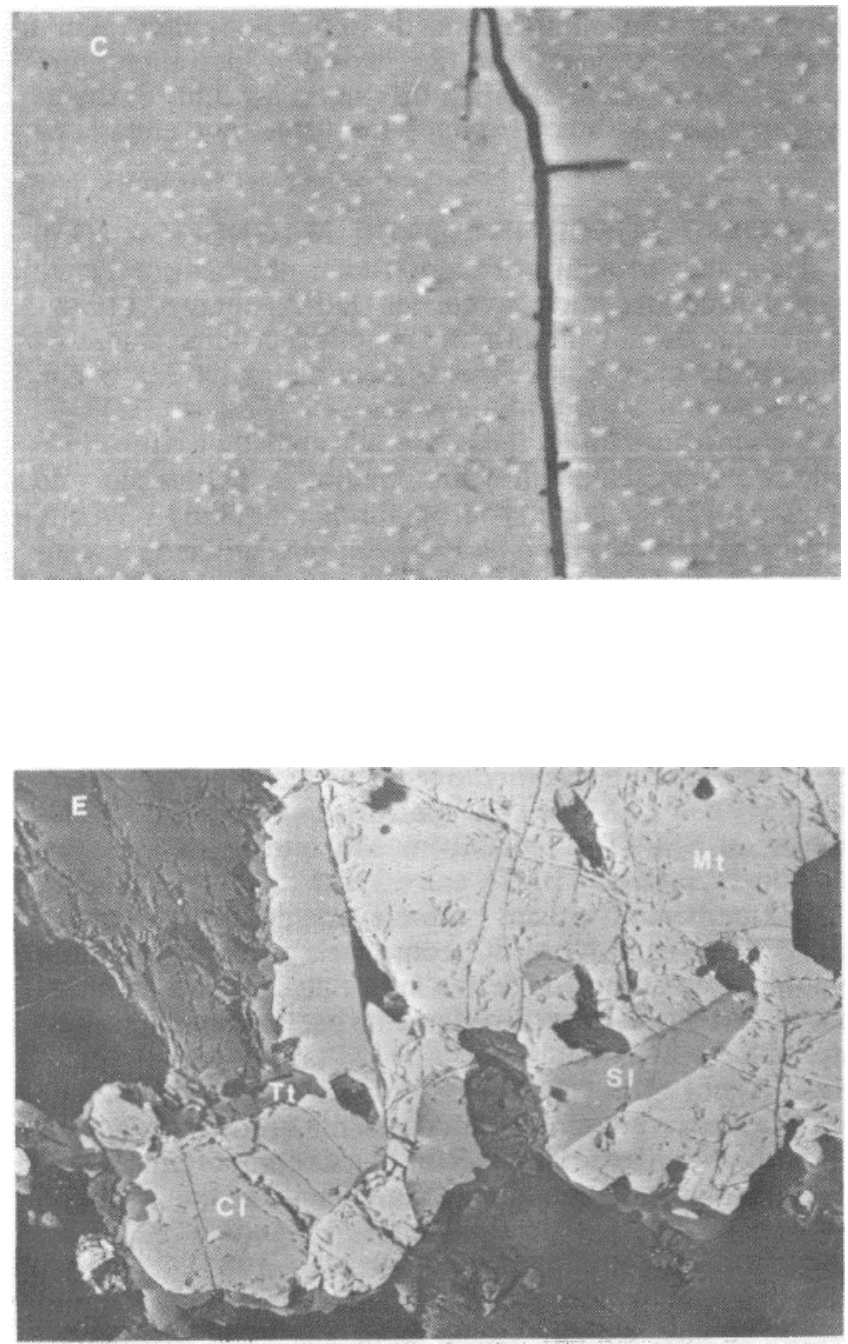

Figura 4 - Aspectos texturais dos óxidos de Fe e Ti (imagens de elétrons retrodifusos obtidos em microscópio eletrônico de varredura), a. Diversos cristais de magnetita (Mt, cinza claro), geralmente envoltos parcialmente por finas auréolas de titanita (Tt, cinza escuro). O cristal maior de magnetita( centro) engloba cristais automorfos de apatita (Ap, quase preto) e possui

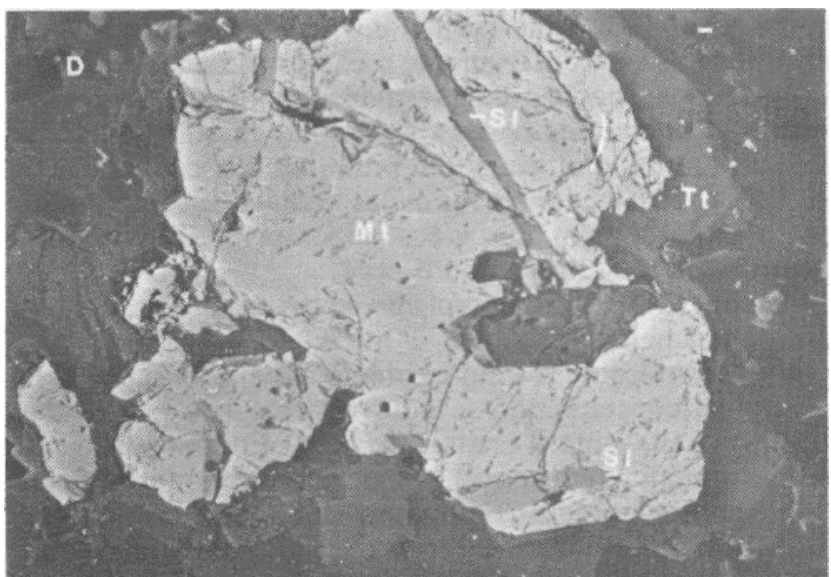

associada ilmenita composite ( $\mathrm{Cl}$, cinza médio) ou em manchas irregulares (PI). O fundo cima escuro é constituido por minerais ferromagnesianos e o preto por félsicos. b. Detalhe do figura anterior mostrando ilmenita composite $(\mathrm{Cl})$, associada à magnetita (MT) e contendo exsoluções de hematita (Hm; cinza claro). Notar a fina auréola de titanita (Tt, cinza escuro) em torno da ilmenita. c. Detalhe da figura anterior, mostrando a presença de finíssimas exsoluções de hematita na ilmenita. d. Cristal de magnetita (Mt, cinza claro), englobando lamelas de ilmenita do tipo sanduíche (SI). Há coroas de titanita envolvendo parcialmente a magnetita. Fundo como na figura $4 a$. e. Magnetita (Mt, cinza claro) associada com ilmenita composite (CI). Notar o contorno denteado do cristal de ilmenita, envolto por fina coroa de titanita (Tt, cinza escuro). Fundo como na figura $4 a$ Figure 4 - Fe-Ti oxide minerals textural aspects (back-scattered electron images obtained on a scanning electron microscope), a. Several magnetite crystals (Mt, light gray), generally showing thin, partial titanite rims ( $\mathrm{Tt}$, dark gray). The largest magnetite crystal (center) includes euhedral apatite crystal (Ap, near black) and has composite ilmenite (CI, medium gray) as well as patches ilmenites, associated to it. Other phases are mafic minerals (dark gray) and felsic ones (black), b. Detail of figure 4a, showing composite ilmenite (CI, associated to magnetite), containing hematite exsolutions (Hm, ligh gray). Note the thin rim of titanite (Tt, dark gray) around ilmenite. c. Detail of figure $4 \mathrm{~b}$, showing exsolution of extremely thin hematite grains in ilmenite. d. Magnetite crystal (Mt; light gray) including sandwich ilmenite (SI) lamellae. Note titanite nms (Tt) partially involving magnetite. Other minerals as in figure 4a. e. Magnetite (Mt, light gray) associated with composite ilmenite (CI). Note the corrosion of ilmenite crystal by titanite (Tt, dark gray). Other minerals as in Figure 4a 
BGD exibe textura granular hipidiomórflca média, tendo os grãos dominantes de 1 a $4 \mathrm{~mm}$ e havendo presença local de cristais mais desenvolvidos de $\mathrm{Fp}(7 \mathrm{~mm})$. $\mathrm{O}$ plagioclásio forma agregados notáveis, onde os demais minerais estão ausentes ou assumem disposição intersticial. A biotita varia de 0,5 a $3 \mathrm{~mm}$. A textura original foi modificada por deformação intensa, responsável por microgranulação e recristalização dos feldspatos nas bordas e fraturas dos seus cristais, pela microgranulação do quartzo e pelo encurvamento das micas e feldspatos. A textura atual tende para o tipo mortar.

O Qz é mais abundante que nos TBMG, formando agregados de cristais xenomorfos, com contatos algo suturados e extinção fortemente ondulante. Apesar da deformação, é possível perceber que os agregados de Qz molduram os plagioclásios, tendendo à disposição intersticial. As mirmequitas são raras e Q $z_{2}$ e Q $z_{4}$ não foram observados nessa rocha.

$\mathrm{O} \mathrm{P} 1$, originalmente subautomorfo a automorfo, assumiu forma ovalada devido à deformação ou tornou-se xenomorfo quando corroído nos contatos com Fp. Mostra forte zoneamento normal e composição análoga à observada nos TBMG. Os núcleos de andesina cálcica $\left(\mathrm{An}_{45 \pm 1}\right)$ passam a andesina sódica $\left(\mathrm{An}_{35 \pm 2}\right)$ e, finalmente, a oligoclasio $\left(\mathrm{An}_{28}\right.$ a 21$)$. As zonas

andesínicas acham-se fortemente corroídas, txibe sempre muitos grãos de epídoto em seu interior, porém, a sericita e os carbonates são relativamente escassos. A descalcifícação do PI limita-se às zonas onde se concentram grãos de epídoto ou às adjacências dos cristais isolados do mesmo. Auréolas albíticas e mirmequíticas estão presentes nos contatos com Fp. Este forma localmente grandes cristais subautomorfos, mas é mais comum em grãos xenomorfos, intersticiais, entremeados aos cristais de P1.

A biotita $(\mathrm{Bt})$ exibe pleocroísmo de amarelo a verde oliva, está praticamente inalterada e foi muito deformada. São comuns grânulos de titanita e epídoto associados a ela, com os últimos concentrando-se notavelmente nas bordas das lamelas da Bt, junto a cristais de P1. O Ep assinalado nas análises modais refere-se apenas àquele associado aos máfícos, não incluindo, portanto, o proveniente da transformação do P1. A Tit também forma cristais milimétricos levemente pleocróicos. Os opacos não são muito freqüentes, mas são bem formados e quadráticos (magnetita?). O zircão parece apresentar superposição de fases de crescimento, como nos TBMG. A apatita é comum na lâmina e foi notada a ocorrência de cristais subautomorfos, esparsos, de turmalina, mineral ausente nas demais rochas da associação.

LEUCOMONZOGRANITOS (LMG) E LEUCO-SIENOGRANITOS (LSG) Este grupo não é homogêneo. Um dos LMG, representado pela amostra UA-13, é bastante similar em textura aos TBMG, embora muito pobre em minerais máfícos. O P1 é andesina-oligoclásio (An ), similar, portanto, ao presente nos TBMG. A allanita forma localmente grandes cristais, assim como a Tit. $\mathrm{O}$ zircão revela duas fases de crescimento e a Bt não difere da descrita nos TBMG. O LMG UA-14 tem textura granular hipidiomórflca, média a fina, tendendo para xenomór- fica. A Bt preserva as características mencionadas nos TBMG; porém, é notável a ausência de Tit e Ap. É muito rico em Qz. O P1, embora não determinado com precisão, parece mais sódico que nos TBMG, e seu hábito também é distinto. Há um acessório incluso no PI, que causa a metamictização deste (monazita?). O LSG (UA-23) é muito rico em Qz; mostra afinidades com os TBMG. Os acessórios aparecem em proporções muito baixas, mas, nos aspectos texturais de detalhe repetem-se feições observadas nos TBMG. O P1 é andesina-oligoclásio e mostra transformação dendrítica ou anastomosada, similar à apresentada pela cordierita em fase de pinitização. Uma possível interpretação é que tais cristais representem resíduos de fusão parcialmente afetados pela anatexia, carreados com líquido formado em

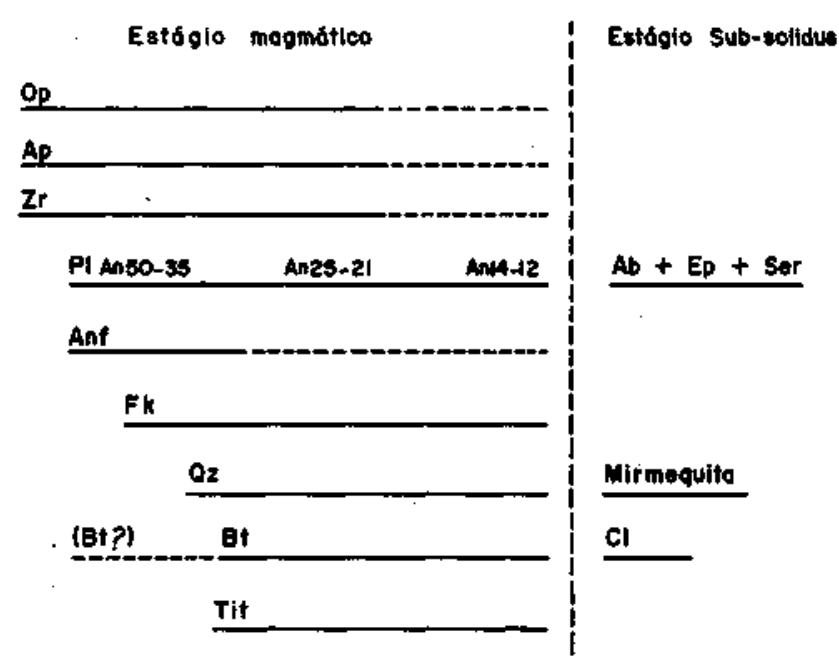

Figura 5 - Ordem de cristalização dos minerais no titanitabiotita monzogranito (TBMG)

Figure 5 - Minerals crystallization order in the titanite-biotite monzogranite (TBMG)

temperaturas não muito acima do solidus, portanto ainda pobre em fases máficas (estas ficariam no resíduo em profundidade). Outra hipótese seria a de que tal aspecto resulte de transformação hidrotermal pouco freqüente, que afetaria de modo mais acentuado o P1.

OPACOS E SUSCETIBILIDADE MAGNÉTICA (SM)

Os dados de SM aqui utilizados foram obtidos por W. A. Sauck e discutidos inicialmente por DalPAgnol et al. (1988). As medidas de SM foram obtidas em superficies planas de amostras de mão, com dimensões mínimas de $3 \times 5 \mathrm{~cm}$, através de um suscetibilímetro modelo Scintrex CTU-2. Diversas medidas foram feitas em cada amostra e o resultado fornecido representa um valor médio. A calibração do aparelho foi efetuada com padrões fornecidos pelo IAG-USP. Magalhães (1991) reviu o fator de correção utilizado inicialmente, adotando-se aqui aquele sugerido por ela. Maiores informações sobre a metodologia podem ser encontradas em Magalhães (1991).

Conforme assinalado anteriormente, os teores modais de opacos são elevados (Tab.l). Nos TBMG eles oscilam entre 0,9 e $3,8 \%$, sendo o teor médio igual a $1,6 \%$. No BGD, o teor é de $0,5 \%$ e nos LMG e LSG ele varia entre 0,5 e $0,1 \%$. Os valores de SM (Tab.l) também são altos para granitos, situando-se, para os TBMG, entre 395,3 e 189,7 x 10-4 (SI). O BGD também possui um valor elevado de SM, similar aos dos TBMG. Nos LMG e LSG, como seria esperado por causa da diminuição acentuada de seu índice de cor e dos teores de opacos, SM decresce acentuadamente oscilando no intervalo entre 108,9 e $21,2 \times 10^{-4}(\mathrm{SI})$.

Dall'Agnol et al. (1988) descutiram o comportamento de SM em diversos granitóides da Amazônia e mostraram que os titanita-biotita granitóides do Rio Uaupés comportam-se para SM como magnetita granitos, assemelhando-se quanto a essa propriedade ao Granito Jamon (Dall'Agnol 1982) e ao Adamelito Água Branca (Jorge-João et al. 1985).

Em diagrama opacos $x$ suscetibilidade magnética (Fig. 6a) percebe-se que, embora exista tendência geral dos pontos indicando correlação positiva entre opacos e SM, não há correspondência perfeita entre o aumento de teor de opacos e o aumento de SM, sobretudo para os TBMG e BGD. Considerando que $\mathbf{l}$. as evidências petrográficas não revelam nessas rochas transformações expressivas que pudessem afetar intensamente os opacos primários e que 2. esses são formados em sua maior parte por magnetita, é possível concluir que os valores próximos de $\mathrm{SM}$ em rochas com teores distintos de 


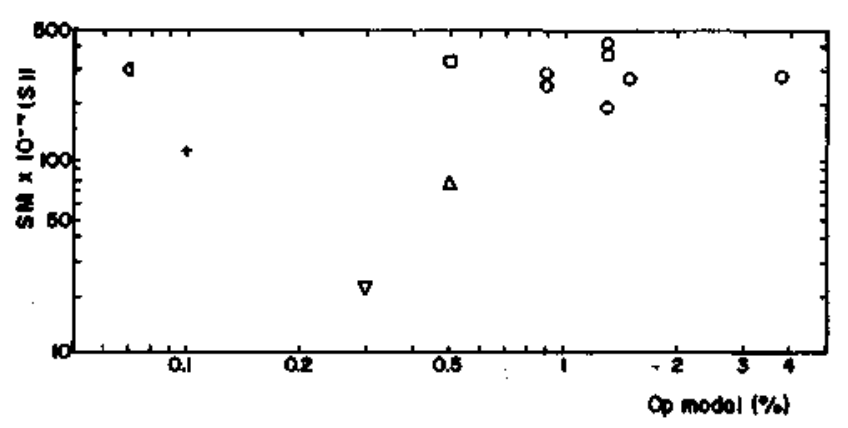

Figura 6 a - Diagrama opacos modais x susceíibilidade magnética do Granito Rio Uaupés (Símbolos conforme Fig. 3)

Figure 6a- Opaque minerals (modal \%) vs. magnetic susceptibility plotof the Rio Uaupés Granite. (Symbols as in Fig. 3)

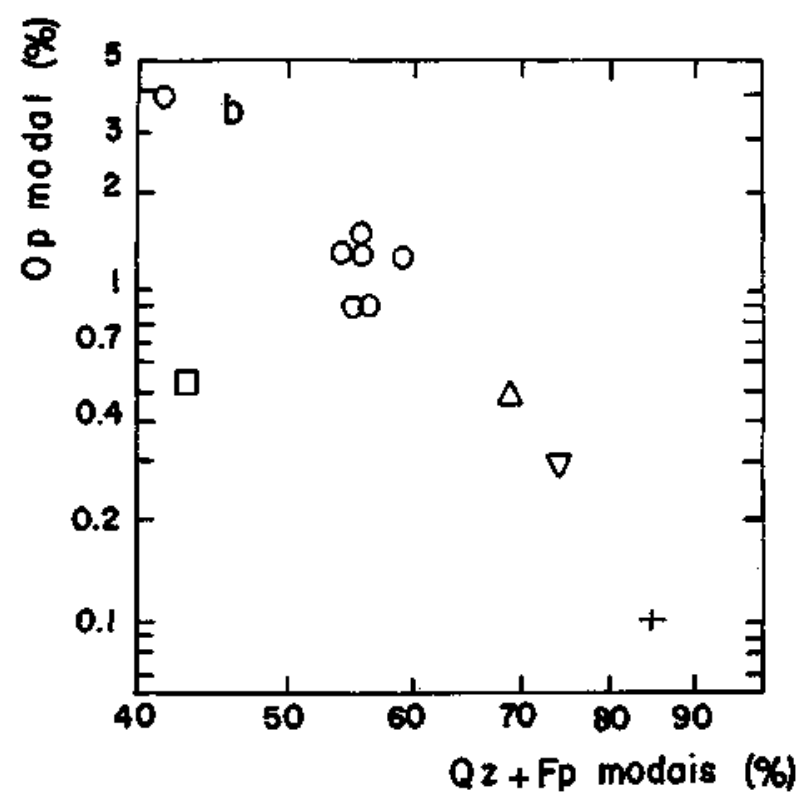

Figura $6 b$ - Diagrama opacos $x$ (quartzo +feldspato potássico) modais do Granito Rio Uaupés (Símbolos conforme Fig. 3) Figure $6 \mathrm{~b}$-Opaqueminerals vsquartz+alkaline feldspar(all inmodal \%)forthe Rio Uaupés Granite. (Symbols as in Fig. 3)

opacos modais podem ser devidos a imprecisões nas determinações das porcentagens dos últimos, eventualmente agravadas pela margem de erro existente nas medidas de SM.

No diagrama (quartzo+feldspato potássico modais) x opacos (Fig. 6b), é constatada correlação negativa muito bem definida, com os teores modais de opacos decrescendo à medida que aumentam aqueles de quartzo+feldspato potássico. Apenas o BGD foge desse padrão, devido ao seu teor modal anomalamente baixo de opacos, talvez mais aparente do que real, conforme discutido acima. Esse diagrama mostra que os teores modais de opacos diminuem à proporção que os granites tornam-se mais leucocráticos, o que implica na existência de proporcionalidade direta entre opacos e constituintes ferromagnesianos.

\section{GEOCRONOLOGIA E AMBIENTE TECTÔNICO}

Para o estudo geocronológico, foi executada seleção preliminar das amostras disponíveis, com base em critérios petrográfícos e na distribuição dos pontos de coleta no campo. Em seguida - sendo considerados os teores de $\mathrm{Rb}$ e $\mathrm{Sr}$ obtidos em análises do laboratório de fluorescência de raios $\mathrm{X}$ da UFPA -, um conjunto de seis amostras foi escolhido para análises espectrométricas. Os teores finais de $\mathrm{Rb}$ e $\mathrm{Sr}$, determinados pelo método de diluição isotópica, e as demais razões necessárias foram obtidos pelo espectrômetro de massa Issomass 54E do Laboratório de Geologia Isotópica da UFPA. Os cálculos de regressão utilizaram a teoria de York (1966, 1969) e o algoritmo de Williamson (1968), com algumas modificações.

Tassinari (1981) apresentou estudo específico sobre a geocronologia da Província Rio Negro. Ele mostrou que os granitóides e gnaisses mineralogicamente afins ao Granito Uaupés concentravam-se em diagrama isocrônico $\mathrm{Rb}-\mathrm{Sr}$, entre as isócronas de referência de 1.750 e $1.500 \mathrm{Ma}$. Segundo esse autor, a dispersão dos pontos sugeria variações nas idades ou diferenças nas fontes das rochas analisadas. Amostras de rochas dominantemente gnáissicas desse conjunto, provenientes de uma região localizada a cerca de $200 \mathrm{~km}$ a NW da região estudada neste trabalho, forneceram, segundo Tassinari (1984), idade de $1709 \pm 17$ Ma com razão inicial $\left({ }^{87} \mathrm{Sr}{ }^{86} \mathrm{Sr}\right)_{0}=0,703 \pm 0,002$, e baixissimo MSWD (Mean Square Weighted Deviation) $=0,0001$. Por sua vez, o método $\mathrm{Pb}-\mathrm{Pb}$ indicou para o mesmo conjunto de amostras idade de $1.632 \pm 250 \mathrm{Ma}$, com $\mathrm{u}^{\wedge}=8,163$, interpretada como indicativa de origem mantélica para os magmas geradores desses ortognaisses. Finalmente, datações U-Pb em zircão (Tassinari \& Van Schmuss inédito, comunicação escrita de C.C.G. Tassinari) resultaram em idades de 1.703 Ma para um titanita-biotita gnaisse e de $1.521 \mathrm{Ma}$ para um granito ou gnaisse porfirítico milonitizado. As duas amostras, datadas pelo método $\mathrm{U}-\mathrm{Pb}$, participam da isócrona $\mathrm{Rb}-\mathrm{Sr}$ que indicou idade de $1.709 \mathrm{Ma}$.

Neste trabalho foram analisados $\mathrm{Rb}$ e $\mathrm{Sr}$ em amostras das diversas fácies do Granito Uaupés. Os resultados obtidos (Tab. 2) mostram no gráfico isocrônico ${ }^{87} \mathrm{Rb} /{ }^{86} \mathrm{Sr}^{87} \mathrm{Sr} /{ }^{86} \mathrm{Sr}$ (Fig. 7) excelente alinhamento dos pontos representativos das amostras, conforme atesta o MSWD igual a 1,05. A correlação apresentada pelas amostras das diferentes fácies reforça a hipótese de sua cogeneticidade. O conjunto de amostras forneceu, assim, idade de $1.459 \pm 32 \mathrm{Ma}$, com razão isotópica ${ }^{87} \mathrm{Sr} /{ }^{86} \mathrm{Sr}$ inicial de $0,70631 \pm 0,00117$, ambas com um sigma de desvio. A ausência de pontos com razões $\mathrm{Rb}-\mathrm{Sr}$ mais baixas, situados próximos à origem da reta isocrônica, reduziu a precisão sobre a razão inicial. A amostra com mais baixa razão $\mathrm{Rb}$-Sr é, paradoxalmente, um leuco-sienogranito, cujo comportamento anômalo geoquimicamente será discutido na segunda parte desta pesquisa. A razão inicial obtida sugere que o magma provém da fusão de materiais crustais ou, alternativamente, da interação de uma fonte mantélica com materiais crustais.

É interessante notar que os titanita-biotita gnaisses datados por Tassinari (1984) apresentam maior idade e razão inicial mais baixa que as obtidas para o Granito Uaupés neste trabalho. Por outro lado, as evidências petrográficas sugerem que os dois grupos de rochas derivam de magmas provenientes da fusão de materiais geoquimicamente similares. Com base nos dados geocronológicos e isotópicos, é possível admitir que rochas derivadas do manto há 2,0 ou $1,9 \mathrm{Ga}$, com razões inciais ${ }^{87} \mathrm{Sr} /{ }^{86} \mathrm{Sr}$ próximas de 0,700 , seriam as rochasfonte dos gnaisses e granitóides. Dessa forma, há 1,7 e 1,45 Ga seriam gerados a partir dessas rochas magmas similares em linhas gerais, com composições isotópicas do estrôncio distintas e correspondentes respectivamente àquelas dos gnaisses e granitóides. Obviamente, para comprovação dessa hipótese são necessários dados adicionais.

As variações de idades obtidas para os titanita-biotita gnaisses e granitóides, tanto pelos métodos $\mathrm{U}-\mathrm{Pb}$, quanto $\mathrm{Rb}-$ $\mathrm{Sr}$, indicam que os mesmos se formaram ao longo de um período de tempo bastante longo, compreendido possivelmente entre $1.750 \pm 50$ e $1.500 \pm 50 \mathrm{Ma}$. Embora os dados sejam limitados, eles sugerem que os gnaisses são mais 
Tabela 2 - Concentrações de Rb e Sr (ppm) e dados isotópicos para o Granito Rio Uaupés Table 2 - $\mathrm{Rb}$ and $\mathrm{Sr}$ contents (ppm) and isotopic data forthe Rio Uaupés Granite

\begin{tabular}{l|c|c|c|c|c|c|c|c}
\hline AMOSTRA & FACIES & RD & S & Rb/Sr & Rb87/Sr86 & $s$ & Rb87/Sr86 & $S$ \\
\hline UA-23 & LSG & 203,1 & 305,0 & 0,67 & 1,933 & 0,020 & 0,746736 & 0,000036 \\
UA-20 & BGD & 204,0 & 248,9 & 0,82 & 2,382 & 0,028 & 0,755869 & 0,000096 \\
UA-08 & TBMG & 210,8 & 251,2 & 0,84 & 2,441 & 0,025 & 0,757690 & 0,000090 \\
$33-A 3$ & TBMG & 248,0 & 280,0 & 0,95 & 2,717 & 0,054 & 0,762149 & 0,000052 \\
$33-A 5$ & TBMG & 248,2 & 217,0 & 1,14 & 3,318 & 0,035 & 0,776715 & 0,0000097 \\
UA-13 & LMG & 323,3 & 222,5 & 1,45 & 4,240 & 0,058 & 0,793652 & 0,000149 \\
\hline
\end{tabular}

antigos que os granitóides sem deformação expressiva, como é o caso do Granito Uaupés. Considerando que o Granito Uaupés não foi afetado pela gnaissifícação, a mesma deve ser mais antiga. Por outro lado, como a idade $\mathrm{U}-\mathrm{Pb}$ dos gnaisses corresponde mais provavelmente àquela de sua formação magmática, é possível admitir que a gnaissifícação tenha se dado entre 1.700 e $1.600 \mathrm{Ma}$, durante o possível estágio sintectônico da colisão continental (?). Outra hipótese seria admitir que a gnaissifícação resulta de deformação durante a colocação de granitóides precoces e não de evento tectonometamórfíco superimposto. Nesse caso, a idade da gnaissifícação seria coincidente com a da colocação de uma primeira geração de granitóides; ambas ocorreriam em torno de $1.700 \mathrm{Ma}$.

O ambiente tectônico da Província Rio Negro tem sido discutido essencialmente com base nos dados geocronológicos e nos limitados dados geológicos disponíveis. Além das hipóteses de Tassinari $(1981,1984)$ e Dall'Agnol et al. (1987), discutidas anteriormente, Gaudette \& Olszewski (1985), com base em dados Rb-Sr e U-Pb obtidos em rochas do Território Federal de Amazonas na Venezuela, admitiram a extensão da Província Rio Negro nessa região e assumiram um modelo envolvendo subducção, com mudança de estilo tectônico de compressional-horizontal para tensional-vertical, e um período de forte metamorfísmo, deformação e intrusão entre 1.860 e 1.760 Ma. Barrios (1983) distinguiu, nessa mesma área, dois eventos tectono-magmáticos com cerca de $1.860 \mathrm{Ma}$ e 1.750 Ma. Priem et al. (1982) estudaram a Amazônia colombiana e identificaram a atuação do Episódio Tectonomagmático Parguazense (1.560-1.450 Ma), o qual causou retrabalhamento meta- mórfico intenso do embasamento transamazônico.

Resumindo: apesar das diferentes concepções e interpretações, os autores citados concordam que essa porção oeste do Escudo das Guianas foi afetada por importante evento tectonometamórfíco e magmático no período entre 1.800 e $1.500 \mathrm{Ma}$, ou seja, após o Ciclo Transamazônico. A limitação dos dados geológicos e estruturais não permite concluir se esse evento envolveu subducção de crosta oceânica ou colisão continental, ou se foi de outra natureza. No momento, os autores deste trabalho inclinam-se mais pela hipótese da ocorrência de colisão continental. Outra possibilidade seria admitir que a PRN foi intensamente retrabalhada no período citado, gerando um cinturão móvel ensiálico, com intenso magmatismo associado (Kröner 1977). Essa questão voltará a ser discutida na segunda parte deste trabalho.

CONCLUSÕES Este trabalho propõe a designação de Granito Rio Uaupés para os titanita-biotita granitóides que ocorrem no baixo curso do Rio Uaupés e que constituem as rochas granitóides dominantes na Província Rio Negro. As evidências disponíveis sugerem a existência no baixo Rio Uaupés de um corpo batolítico formado dominantemente por

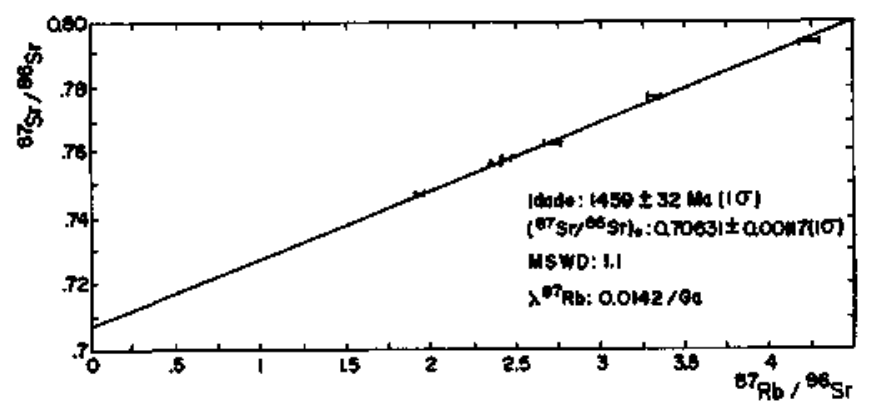

Figura 7 - Diagrama isocrônico Rb-Sr do Granito Rio Uaupés Figure 7 - Rb-Sr isochronic diagram of the Rio Uaupés Granite

titanita-biotita monzogranitos (TBMG), acompanhados por biotita granodioritos (BGD), leucomonzogranitos (LMG) e leucos-sienogranitos (LSG). Os aspectos petrográficos mais marcantes nessas rochas são: teores pouco elevados de quartzo; conteúdos relativamente elevados de anortita nos seus plagioclásios; proporções modais excepcionalmente elevadas de titan ita + opacos + apatita (igual em méd ia a $4,7 \%$ no TBMG).

A análise textural revelou que opacos, apatita e zircão são as primeiras fases a cristalizar, seguindo-se plagioclásio andesínico e anfíbólio. Com o abaixamento da temperatura do magma, começam a se formar sucessivamente feldspato alcalino dominantemente potássico, quartzo e titanita. A biotita mostra relações texturais ambíguas, ora sugerindo sua formação precoce, ora muito tardia. O plagioclásio em equilíbrio com feldspato potássico e quartzo tinha provavelmente composição de oligoclásio cálcico e, no final da cristalização, formaram-se estreitas bordas de oligoclásio sódico. As transformações tardi e pós-magmáticas são muito discretas, limitando-se à formação local de albitai epídoto+sericita a partir do plagioclásio, de intercres- cimentos mirmequíticos e de alguma clorita em lugar da biotita.

O Granito Rio Uaupés possui valores bastante elevados de suscetibilidade magnética e é muito rico em opacos, entre os quais predomina a magnetita, acompanhada por ilmenita \pm pirita. Enquadra-se, portanto, entre os granitos da série com magnetita. Neste aspecto, assemelha-se ao Adamelito Água Branca e ao Granito Jamon (Dall'Agnol et al. 1988). Nas amostras estudadas, há correlação negativa muito clara entre os teores modais de opacos e de quartzo+feldspatos, mostrando que os primeiros diminuem à medida que a rocha vai se tornando mais leucocrática. No gráfico teor modal de opacos versus suscetibilidade magnética, esboça-se correlação positiva, mas ela não é respeitada por todas as amostras.

Foi obtida, por meio do método $\mathrm{Rb}-\mathrm{Sr}$ em rocha total, idade 
isocrônica de $1459 \pm 32 \mathrm{Ma}$, interpretada como sendo a idade de cristalização desse corpo. A razão inicial ${ }^{87} \mathrm{Sr} /{ }^{86} \mathrm{Sr}$, igual a $0,70631 \pm 0,00117$ foi considerada como indicativa de origem crustal para o magma ou, alternativamente, de origem mantélica com forte contaminação crustal. Essa idade difere bastante daquela obtida por Tassinari (1984) para titanitabiotita gnaisses da Província Rio Negro, bastante similares em termos de associação petrográfica aos titanita-biotita granitóides. Isso, aliado aos dados U-Pb em zircões fornecidos pelo referido pesquisador, que indicam idades próximas de 1.700 e 1.500 Ma para as mesmas rochas estudadas por ele pelo método $\mathrm{Rb}-\mathrm{Sr}$, leva à conclusão que os gnaisses seriam mais antigos que o Granito Rio Uaupés. Estes autores consideram, portanto, que houve a colocação de granitóides similares ao Granito Rio Uaupés em torno de $1.700 \mathrm{Ma}$, os quais foram, quando da sua colocação ou pouco tempo após, gnaissifícados. O Granito Rio Uaupés seria formado em torno de $1.450 \mathrm{Ma}$, a partir de um material similar ao que originou os gnaisses, com maior tempo de residência crustal.

Os dados de mapeamento geológico e os estudos estruturais são totalmente insuficientes para permitirem a definição do ambiente tectônico da Província Rio Negro. Além disso, esta discussão será aprofundada na segunda parte desse trabalho.
Não esquecendo essas restrições, dentre as várias hipóteses apresentadas até o momento para explicar a evolução da Província Rio Negro, foi preferido o modelo de colisão continental, por ser, no entender dos autores, aquele que melhor se coaduna aos dados disponíveis.

Agradecimentos Os autores agradecem a J.M. Lafon e T. Scheller, pelas discussões e por sugestões recebidas; a W. A. Sauck, pelas medidas de suscetibilidade magnética; a M.S. Magalhães, pelas correções nas medidas de SM por causa dos novos fatores introduzidos e pelo auxílio nas determinações dos minerais opacos ao microscópio óptico e eletrônico; a Companhia Brasileira de Metalurgia e Mineração (CBMM) e particularmente a B. Riffel, pelo apoio na realização do estudo de minerais opacos por meio do microscópio eletrônico de varredura; a C.C.G. Tassinari, por informações inéditas e por discussões mantidas; aos colegas do projeto 1GCP-204, por discussões na fase inicial desse trabalho; a C.M.G. Silva, pela elaboração de diagramas em computador; a D. P. Almeida, pela datilografia do texto; aos desenhistas do $\mathrm{CG}$, por sua parcela de trabalho. Essa pesquisa recebeu apoio financeiro do PADCT-FINEP (Projeto 4.3.87.0911.00) e, em sua fase inicial, do Projeto IGCP-204 (1UGS-UNESCO).

\section{REFERÊNCIAS BIBLIOGRÁFICAS}

ANDERSON, J.L. \& BENDER, E.E. 1989. Nature and origin of Proterozoic A-type granitic magmatism in the southwestern United States of America. Lithos, 23:19-52.

BARRIOS, F.J. 1983. Caracterização geocronológica da região amazônica da Venezuela. São Paulo. 123p. (Dissertação de Mestrado, IG/USP).

BORREL, A. 1978. Lê massif granitiqueduSidobre:pétrographie, estructure, relations mise-en-place-cristallisation. Toulouse. $131 \mathrm{p}$. (These de Doctoral, Laboratoire deGéologie-Pétrologie, Université Paul Sabatier).

BOWDEN, P.; BATCHELOR, R.A.; CHAPPELL, B.W.; DID1ER, J. LAMEYREJ. 1984. Petrological,geochemical,andsourcecriteriaforthe classification of granitic rocks: a discussion. Phys. of the Earth Planet. Int. 35:1-11

CHAVES, F. 1956. Petrographic modal analysis. New York, Wiley \& Sons. $113 \mathrm{p}$

CORDANI, U.G. \& BRITO-NEVES, B.B. 1982. The geologic evolution of South America during the Archaean and Early Proterozoic. Rev. Bras. Geoc., 12(1-3):78-88.

DALL'AGNOL,R. 1982. MaciçoJatnon:evoluçãopetrológicadeumgranito daAmazôniaOriental.In:SIMP.GEOL. AMAZ., 1.Belém, 19\&2.Anais.. Belém, SBG,v.2, p. 139-161.

DALL'AGNOL, R. As rochas granitóides e gnáissicas do extremo $\mathrm{N} \mathrm{Wdo}$ território brasileiro (/ronteiracom Colômbiae Venezuela): umarevisão. Belém. 20 p. (Contribuição parao projeto IGCP-204) (Inédito).

DALL'AGNOL, R. \& ABREU, A.S. 1976. Características petrográficas e petrológicas do Complexo Guianense da Folha NA. 19 Pico daNeblina. In: CONGR BRAS.GEOL, 29. Ouro Preto, 1976. Anais Ouro Preto, SBG. v.2, p. $321-350$

DALL'AGNOL, R.; BETTENCOURT, J.S.; JORGE-JOÃO, X.S.; MEDEIROS, H.; COSTI,H.T.;MACAMBIRA,M.J.B. 1987. Granitogenesis in the Northern Brazilian region: a review. Rev. Bras.Geoc., 17(4):382-403.

DALL'AGNOL, R.; SAUCK, W.A.; GONÇALEZ, M.G.B. 1988. Suscetibil idade magnética em granitóides da Amazônia: um estudo prel iminar. In: CONGR. BRAS. GEOL., 35. Belém, 1988. Anais... Belém, SBG. v.3, p. 1164-1173.

DOWTY,E 1980. Synneusis reconsidered $\mathrm{Co}>\mathrm{tfnf} \mathrm{M}^{\wedge} \mathrm{ra} / \mathrm{W} /-\mathrm{O} /, 74: 75-84$

FERNANDES, P.E.C.A.; PINHEIRO, S.S.; MONTALVÃO, R.M.G.; ISSLER R.S.; ABREU, A.S.; TASSINARI, C.C.G. 1977. Geologia. In: MME PROJETO RADAMBRASIL ed. Levantamento de Recursos Naturais Folha SA. 19Içá. Riode Janeiro, DNPM. p. 17-123. (v. 17).

GAUDETTE,H.E.\&OLSZEWSKI,W.J.,Jr. 1985. Geochronology of the basement rocks, Amazonas Territory, Venezuela, and the tectonicevolution of the Western Guiana Shield. Geol. Mijnbouw, 64:131 -143.

HARRIS, N.B.W ; PEARCE, J.A. TINDLE, A.G. 1986 Geochemical characteristics of collision-zone magmatism. In: COWARD, M.P. \& RIES, A.C. eds. Collision tectonics, p. 67-81 (Geol. Soc. Special Publ., 19).

ISHIHARA, S. 1981. The granitoid series and mineralization. Econ.Geol., 75:458-484.

ISSLER, R.S. \& LIMA, M.IC. 1987. Amazonic Craton(Brazil) granitogenesis and its relation to geotectonic units. Rev.Bras.Geoc, 17(4):426-441.

JORGE-JOAO,X.S.;SANTOS,C.A.;PROVOST,A. 1985. Magmatismoadamelitico Agua Branca (Folha Rio Mapuera, N W do Estado do Pará). In: SIMP. GEOL. AMAZ.,2. Belém, 19\&5.Anais... Belém,SBG. v.2,p.93-109.

KRÖNER, A. 1977. The Precambrian geotectonic evolution of Africa: plate acretion versus plate destruction. Precambrian, 4:163-213.

LIMA, MIIC. \& PIRES, JL. 1985. Geologia da região do Alto Rio Negro AM.In:SIMP.GEOL.AMAZ.,2.Belem, 1985. /1/ja/1́... Belém, SBG. v. 1 p. $140-154$

MAGALHÃES, M.S. 1991. Minerais Opacos e susceptibilidade magnética de granitóides da Amazônia Oriental: implicações petrológicas Belém. 274 p. (Dissertação de Mestrado, Centro de Geociências/UFPA).

MAGALHÂES, M.S. \& DALL'AGNOL, R. inéd. -Estudos de minerais opacos e suscetibilidade magnética nos granitos Musa e Jamon (região de Rio Maria- SE do Pará) e suas implicações petrológicas. (submetidoàRev. Brás. Geoc.).

MANI AR, P.D. \& PICCOLI, P.M. 1989. Tectonic discrimination of granitoids. Geol.Soc. America Bull., 101:635-643.

PAIVA, G. 1929. Valle do Rio Negro; Physiografia e geologia. Rio de Janeiro, Serv. Geol. Miner. 62 p. (Boletim 40).

PEARCE, J.A.; HARRIS, N.B.W ; TINDLE, A.G. 1984 Trace element discrimination diagrams for the tectonic interpretation of graniticrocks.7. e/ro/ogy, 25(4):956-983.

PINHEIRO, S.S.; FERNANDES, P.E.C.A.; PEREIRA, E.R.; VASCONCELOS, E.G.; PINTO, A.C.; MONTALVÃO, R.M.G.; ISSLER, R.S. DALL'AGNOL, R; TEIXEIRA, W ; FERNANDES, C.A.C. 1976 Geologia. In: MME. PROJETO RADAMBRASIL aâ. Levantamento de Recursos Naturais. Folha NA. 19 - Pico da Neblina. Rio de Janeiro. DNPM, p. 17-137. (v. 11).

PRIEM, H.N.A; ANDRIESSEN, P.A.M ; BOELRIJK,N.A.I.M ; BOORDER, H.HEBEDA,E.H.HUGUETT, A ;VERDURMEN, E A T.H.VERSCHURE,R.H. 1982. Geochronology of the Precambrian in the Amazonas RegionofsoutheasternColombia(WestemGuianaShield).Geo/.A///"«6oMw, 61:229-242.

RAMBERG,H. 1962. Integranularprecipitation of albite formed by unmixing ofalkali-feldspar.A^.Mnmj/./iW?., 98:14-34

ROGERS,J.J.W.\&GREENBERG,J.K. 1990. Laie-orogenic,post-orogenic, and erogenic granites: distinction by major-element and trace-element chemistry and possible origin. J. Geol., 98(3):291 -309.

SMITH, J.V. 1974. Feldspar minerals: chemical and texturalproperties. New York. Springer Verlag. v. 2, 690 p.

SMITH, J.V. \& BROWN, W.L. 1988. Feldspar minerals. Crystal structures, physical, chemical and textural properties. 2ed. Berlin, Springer Verlag. v. $1,828 \mathrm{p}$

STAMATELOPOULOU-SEYMOUR, $\mathrm{K} \cdot$ VLASSOPOULOS, D ; PEARCE T.H.; RICE, C. 1990. The record of magma chamber processes in plagioclase phenocrysts at Thera volcano, Aegean volcanic arc, Greece. Contrib. Mineral. Petrol., 104:73-84.

STRECKEISEN,A.L. 1976. Toeachplutonicrockitspropername.£ar//;Scf. 7?E-V., 12:1-33.

TASSINARI,C.C.G. 1981. Evolução geotectônica da Província Rio NegroJuruena na região Amazônica. São Paulo. 99 p. (Dissertação de Mestrado, IG/USP).

TASSINARI C.C.G. 1984. A porção ocidental do Cráton Amazônico: evidências isotópicasdeacreção continental no ProterozóicoMédio. In: SIMP AMAZ 2 Manaus, 1984. Anais... Manaus, DNPM MME. p. 439-446.

TEIXEIRA, W.; TASSINARI, C.C.G.; CORDANI, U.G.; KAWASHITA, K. 1989. A review of the geochronology of the Amazonian Craton: tectonic implications. Precambrian Res., 42:213-227. 
TSUCHIYAMA,A. 1985. Dissolutionkineticsofplagioclaseinthemeltofthe system diposide-albite-anorthite, and origin ofdustyplagioclase in andesites. Contrib. Mineral. Petrol., 89:1-16.

VANCE, J.A. 1965. Zoning in igneous plagioclase: patchy-zoning. J. Geol., 73(4):636-651.

VANCE, J.A. 1969. On synneusis. Contrib, Mineral. Petrol., 24:7-29.

WILLIAMSON, J.H. 1968. Least-squares fitting of a straight line. Can. J. Phys., 46:1845-1847.

YORK, D. 1966. Least-squares fittingofastraightline. CanJ. Phys.. 44:1079-1086.
YORK, D. 1969. Least-squares fitting of a straight line with correlated errors. Earth Planet. Sci. Let., 5:320-324.

MANUSCRITO A704

Recebido em 24 de julho de 1991 Revisão do autor em 20 de janeiro de 1992 Revisão aceita em 20 de janeiro de 1992 